\title{
Impact of nano-silicon fuel additive on combustion, performance and emission of a twin cylinder $\mathrm{Cl}$ engine
}

\author{
Anand Kumar S A ${ }^{1, *}$, Raja $\mathrm{V}^{1}$, Dhivakar Raviram $\mathrm{R} \mathrm{P}^{2}$, and Sakthinathan $\mathrm{G}^{1}$ \\ ${ }^{1}$ Department of Production Technology, Madras Institute of Technology, Chennai, India \\ ${ }^{2}$ Saveetha School of Engineering, Saveetha Institute of Medical and Technical Sciences, Chennai, India
}

\begin{abstract}
Combustion characteristics of a fuel defines its performance and emission characteristics. Enhancement of combustion characteristics is feasible by improvisation of fuel properties. Fuel additives were used for varying fuel properties. The evolution of 'nano-concept' develops countless applications in the existing technologies. In this experiment silicon nanoparticles were synthesized by ball milling micron sized silicon particles for 45 hours. The elemental and structural characterizations for the additive material were carried out by EDS, SEM and TEM analysis. Silicon nano additive was mixed in three different weight proportions with diesel to prepare the test fuels. The fuel properties variation with the addition of nano additive were studied. Engine testing was carried out at constant $1200 \mathrm{rpm}$ speed and varying load conditions. Diesel fuel added with $0.5 \mathrm{wt} \%$ Si nanoadditive (Si 0.5 ) showed maximum load carrying ability among the different test fuels. In comparison with diesel at $1200 \mathrm{rpm}$ and $100 \%$ load condition, an increase in torque of $5.91 \%$ was observed and BTE was increased by $8.93 \%$ with a decrease in $\mathrm{NO}_{\mathrm{x}}$ emission by $27.3 \%$. Variation in the performance and emission characteristics of the fuels were the results of change in heat release rate and combustion timing with the addition of nano additives which could be studied from the combustion characteristic curves.
\end{abstract}

Keywords: Combustion Analysis, Fuel Additive, Nano-fuel, Silicon Nanomaterial

\section{Introduction}

The rapid development in technology increases the energy requirement which leads to the development of new energy sources as well to find an efficient way of using them. Enhancing the fuel properties results in efficient utilization of energy stored in a fuel.

The volumetric or gravimetric energy content of metals are considerably higher than the energy densities of traditional liquid fuels [1]. The combustion of metals has long been of interest to the combustion community because of their high energy density [2, 3]. Combustion of liquid fuels mixed with metals release high combustion energies. Many researchers investigated the combustion effect of such fuels called 'slurry fuels'. Slurry fuels are liquid hydrocarbon fuels loaded with micron sized metallic particles $(40-80 \%$ by weight) [1].

The practical application of slurry fuels are limited, because of incomplete combustion, lower combustion efficiency, deposits in the combustion chamber and increased particulate emissions [1]. The slurry fuels doesn't form a stable solution, since the micron sized metal particles settle down by gravity. This causes incomplete combustion and increased particulate emission.

The advancement in nanotechnology enable production, control and characterization of nanized metallic particles. Nanosized metallic powders possess high specific area, which lead to high reactivity [4]. Using nanoscale energetic materials as fuel additive to enhance combustion of liquid fuels is an interesting concept.

Nano-fuels are liquid fuels in which low concentrations of metal and metal oxide (Al, B, C, Mg, $\mathrm{Mn}, \mathrm{Fe}, \mathrm{CeO}_{2}$ and $\mathrm{Al}_{2} \mathrm{O}_{3}$ ) nanopowders (size ranges between $10-210 \mathrm{~nm}$ ) are dispersed to form a stable solution [5-7]. Nanoparticles form a more stable suspension than microparticles. While the thermophysical properties are not greatly affected since concentration and size of the particles in nano-fuels are small.

Previous studies have demonstrated significant improvements using such nano-fuels including higher energy release, increased ignition probability, improved burning rates, enhanced catalytic effects and shortened ignition delay [5, $7 \& 8$ ]. Based on these developments, research in the relatively new area of nano-fuels has

Corresponding author: anandkumar0412@gmail.com 
become a topic of significant interest. It is clear that soon many areas of combustion will be influenced by nanotechnology as a result of future fuels, propellants, pyrotechnics, explosives and reactive materials having nanoscale features.

Diesel fuel refined from crude oil is a well-known commercial and industrial fuel. In this research work, nano-fuel is prepared with silicon nanoadditive in diesel base fuel. Three test fuels were prepared with three different weight ratios of silicon nanoadditive. The prepared nano-fuels were tested in a twin cylinder diesel engine to study the effect of nanoparticle in the combustion, performance and emission of the base fuel.

\section{Synthesis and Characterization of Nanoadditive}

The stoichiometric combustion reaction of diesel fuel is generally represented as

$$
\mathrm{C}_{12} \mathrm{H}_{23}+17.75 \mathrm{O}_{2}+66.97 \mathrm{~N}_{2} \rightarrow 12 \mathrm{CO}_{2}+11.5 \mathrm{H}_{2} \mathrm{O}+66.97 \mathrm{~N}_{2}
$$

The bonds between $\mathrm{C}$ and $\mathrm{H}$ atoms in the fuel were broken and new bonds were formed with oxygen. The formation of the products $\mathrm{CO}_{2}$ and $\mathrm{H}_{2} \mathrm{O}$ by the oxidation of $\mathrm{C}$ and $\mathrm{H}$ atoms releases excessive heat energy. This oxidation reaction is called combustion reaction. Based on this, a material which releases more energy during oxidation reaction was chosen as additive.

Several materials like $\mathrm{B}, \mathrm{Al}, \mathrm{Mg}, \mathrm{Mn}$, and Fe were used as additives by several researchers [3, 5, 9-12]. In this work silicon is used, which is easily available at low cost. Silicon releases more energy than carbon and hydrogen during oxidation. The bond energy of the combustion reactants are given in the Table 1 .

Table 1. Bond Energy of Combustion Reactants

\begin{tabular}{ccc}
\hline Material & Bond & $\begin{array}{c}\text { Bond Energy } \\
\mathbf{k J} / \mathbf{m o l}\end{array}$ \\
\hline Carbon & C-O & 360 \\
Hydrogen & H-O & 428 \\
Silicon & Si-O & 798 \\
\hline
\end{tabular}

Microsized silicon particles were milled in a planetary ball mill for 45 hours at $300 \mathrm{rpm}$ speed. Tungsten carbide vial and balls were used for milling. 20:1 ball to material weight ratio was followed.

The unmilled silicon particles were analysed in Scanning Electron Microscope to check the size of the particles. Energy Dispersive Spectrum analysis was done to confirm the chemical composition of the additive material. Transmission Electron Microscope images of the milled silicon particles were taken to confirm the particle size after milling.

\section{Nano-fuel Preparation}

The synthesized silicon nanoparticles were mixed with diesel in three different weight ratios $(0.25 \mathrm{wt} \%, 0.5$ $\mathrm{wt} \%$ and $0.75 \mathrm{wt} \%$ ). So that, the effect of concentration of the nanoadditives in the base fuel could be analysed. The nanosized particles formed a stable solution with the diesel neglecting gravitational effect. Figure 1 shows the base fuel and nano-fuel.

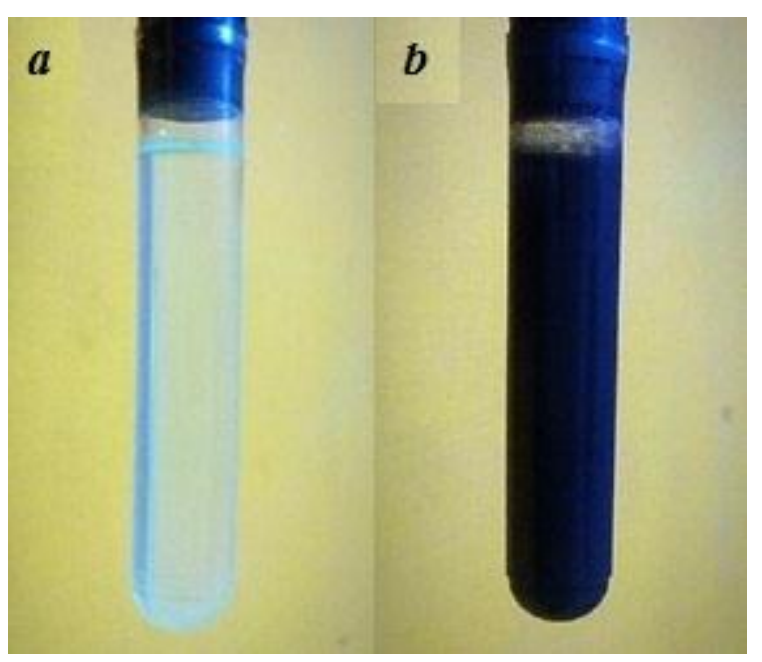

Fig. 1. Base fuel and nano-fuel

The thermal properties of nano-fuels were characterized by ASTM standard D 445 test method for kinematic viscosity, ASTM standard D 4052 test method for specific gravity, ASTM standard D 93 test method for flash point, ASTM standard D 240 test method for calorific value.

\section{Engine Testing}

For effective analysis of the prepared nano-fuel, it is essential to test the fuel in an engine for sufficient number of times at different load conditions. It is necessary to check the combustion, performance and emission characteristics of the fuel in an engine under actual working conditions. The experimental setup used is shown in the Figure 2.

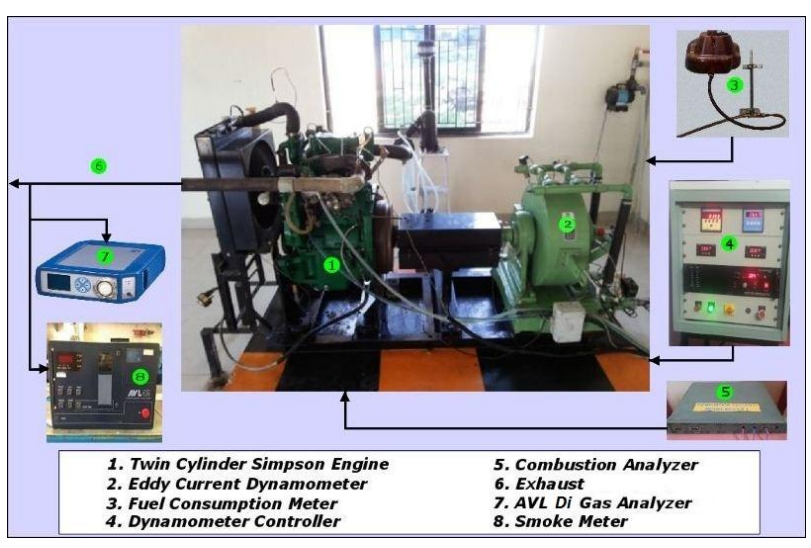

Fig. 2. Engine testing setup 
A twin cylinder direct injection diesel engine of Simpsons coupled with AVL eddy current dynamometer was used for this study. The engine was operated at a constant $1200 \mathrm{rpm}$ speed with varying load conditions namely $0 \%, 25 \%, 50 \%, 75 \%$ and $100 \%$. The technical specifications of the engine are listed in the Table 2. The exhaust emissions were analysed by an AVL Di Gas Analyzer and a smoke meter.

Table 2. Specification of the test Engine

\begin{tabular}{ll}
\hline Engine & Simpsons S 217 \\
Number of cylinders & 2 \\
Configuration & Vertical in-line diesel engine \\
Capacity & $21 \mathrm{~kW}(28 \mathrm{bhp} @ 2000 \mathrm{rpm})$ \\
Compression ratio & $18.5: 1$ \\
Cooling system & Water \\
Displacement & $1670 \mathrm{cc}(127 \mathrm{~mm} * 91.44 \mathrm{~mm})$ \\
Injection timing & $30^{\circ} \mathrm{BTDC} @ 200 \mathrm{bar}$ \\
Nozzle hole number & 3 \\
Nozzle hole diameter & $0.3 \mathrm{~mm}$
\end{tabular}

Experiments were performed in a randomized design. A total of 20 tests (4 fuel $\times 5$ loads) were performed in three replications to get an accurate reading. Initially the engine was operated for 30 minutes to achieve steady state condition. It was confirmed by the evaluation of coolant and lubricant temperature. The accuracy of the measured parameters are given in Table 3.

Table 3. Uncertainty in the measured data

\begin{tabular}{ll}
\hline \multicolumn{1}{c}{ Parameter } & \multicolumn{1}{c}{ Uncertainty } \\
\hline Engine Speed & $\pm 4 \mathrm{rpm}$ \\
Temperatures & $\pm 6.5^{\circ} \mathrm{C}$ \\
Pressure & $\pm 1 \mathrm{bar}$ \\
Crank angle encoder & $\pm 1^{\circ}$ \\
$\mathrm{CO}$ & $\pm 0.2 \%$ \\
$\mathrm{HC}$ & $\pm 10 \mathrm{ppm}$ \\
$\mathrm{NO}_{\mathrm{X}}$ & $\pm 20 \mathrm{ppm}$
\end{tabular}

\section{Results and Discussion}

The structural and chemical characterization of the synthesized nanoparticles, the physicochemical properties of the prepared nano-fuel are discussed. The results of the experimental studies on the effect of the silicon nanoparticle in engine analysis is also discussed.

\subsection{Nanoadditive Characterization}

The particle size analysis of the silicon used in this research work was done before and after milling by SEM and TEM respectively. To confirm the chemical composition EDS analysis was done.

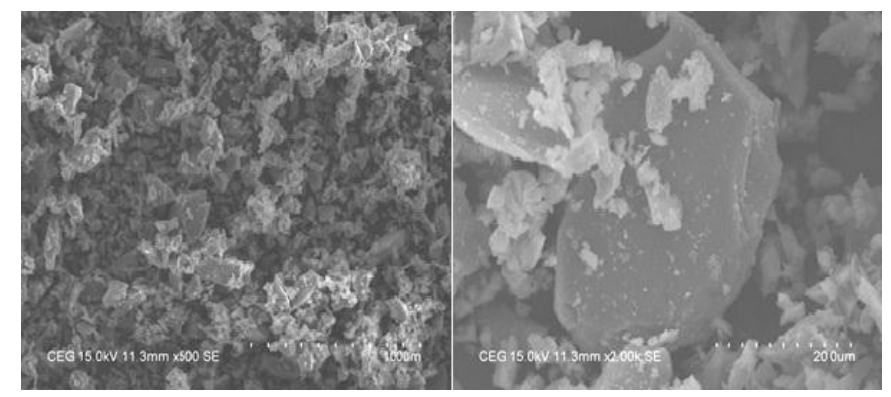

Fig. 3. SEM images of unmilled silicon microparticles

The SEM analysis was done before milling. The SEM images of particles before milling at two different magnifications are provided in the Figure 3 . From the figure it is clarified that the particles doesn't provide uniform size and structure. The size of the particles vary in between $2 \mu \mathrm{m}$ and $30 \mu \mathrm{m}$.

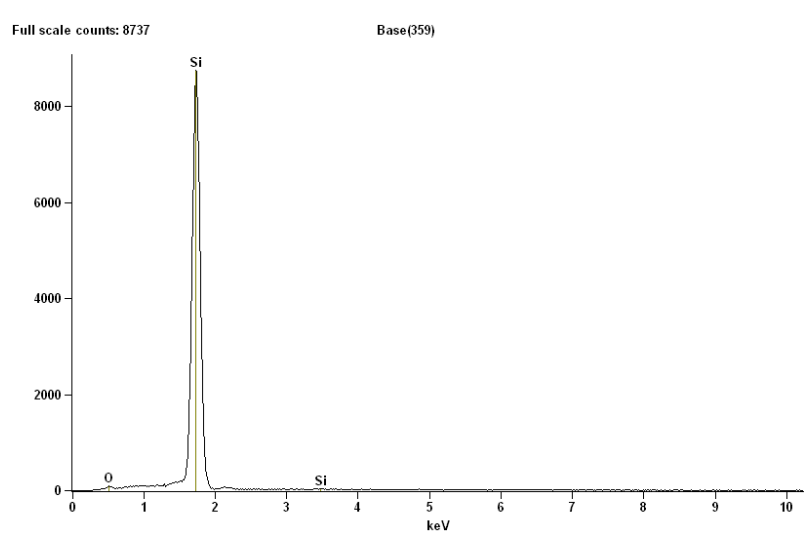

Fig. 4. EDS analysis of Silicon

The EDS spectrum of silicon is presented in the Figure 4 . The elemental composition of sample material obtained from the EDS analysis is given in Table 4. The silicon used in this work is $97.89 \%$ pure. Slight oxidation of upto $2.11 \%$ is seen in the particles. The effect of the oxidation of silicon particles is negligible during combustion.

Table 4. EDS report for Si chemical composition

\begin{tabular}{cccc}
\hline Element & Net Counts & Weight \% & Atom \% \\
\hline $\mathrm{O}$ & 481 & 2.11 & 3.65 \\
$\mathrm{Si}$ & 111535 & 97.89 & 96.35 \\
Total & & 100.00 & 100.00 \\
\hline
\end{tabular}


Silicon microparticles were milled for 45 hours in the ball mill and analyzed in TEM for testing the particle size. It could be observed from Figure 5 that, the indefinite shaped microsized silicon particles was transformed into spherical and rod shaped nanoparticles after milling. The size of the particles vary between 60 $\mathrm{nm}$ and $100 \mathrm{~nm}$. These nanoparticles were used to prepare a stabilized nano-fuel solution.

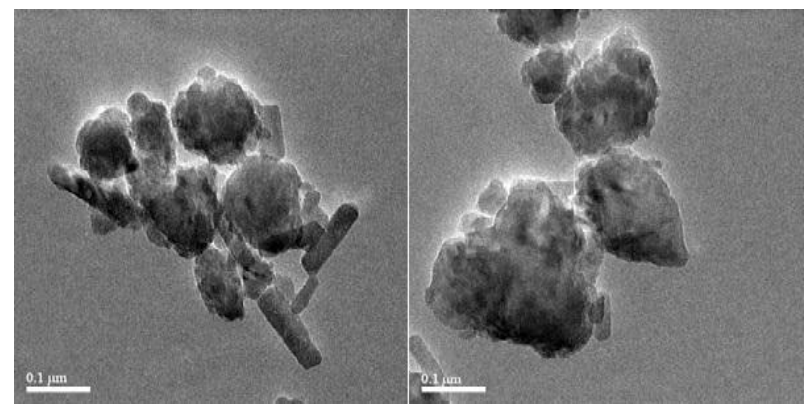

Fig. 5. TEM images of silicon nanoparticles

\subsection{Nano-fuel Characterization}

The test fuels prepared with three different composition of silicon nanoparticles were further analyzed to find the variation in its physicochemical properties with respect to the addition of nanoadditives. The variation in the physicochemical properties are provided in Table 5.

Table 5. Physicochemical properties of the test fuels

\begin{tabular}{ccccc}
\hline \multirow{2}{*}{ Fuel } & $\begin{array}{c}\text { Calorific } \\
\text { Value } \\
\text { MJ/kg }\end{array}$ & $\begin{array}{c}\text { Specific } \\
\text { Gravity }\end{array}$ & $\begin{array}{c}\text { Kinematic } \\
\text { Viscosity } \\
\text { @4 }{ }^{\circ} \mathbf{C} \\
\text { cSt }\end{array}$ & $\begin{array}{c}\text { Flash } \\
\text { Point } \\
{ }^{\circ} \mathbf{C}\end{array}$ \\
\hline ASTM & D240 & D4052 & D445 & D93 \\
\hline Diesel & 42.891 & 0.831 & 2.73 & 79 \\
Si 0.25 & 43.478 & 0.8331 & 2.79 & 76 \\
Si 0.5 & 43.731 & 0.8352 & 2.82 & 71 \\
Si 0.75 & 43.789 & 0.8372 & 2.87 & 73 \\
\hline
\end{tabular}

The quantity of silicon nanoadditives added were very small $(0.25 \mathrm{wt} \%, 0.5 \mathrm{wt} \%$ and $0.75 \mathrm{wt} \%)$. With the addition of nanoadditives a slight increase in the calorific value, specific gravity and viscosity were observed [13]. While the flash point is found to show a decreasing trend for the first two samples and it is increasing on further addition of nanoadditive.

The high energy content and reactivity of the silicon nanoparticles lead to the increase in calorific value of the fuel. As the $\mathrm{wt} \%$ of the particle was increased the specific gravity and the viscosity of the fuels were also increased. Addition of silicon nanoparticles decreases the flash point of the fuel. As reported by several researchers the decrease in flash point attributes the shortened ignition delay of metals. At $0.75 \mathrm{wt} \%$ an increase in flash point is observed. Increase in concentration of particles leads to increase in agglomeration probability. Increase in agglomeration reduces the specific surface area of the reactive material. This is the probable cause for the reduction in flash point.

\subsection{Combustion Analysis}

The combustion characteristics of a fuel can be studied in detail from ignition delay of the fuels, heat release rate curve and P- $\Theta$ curve. The ignition delay of the tested fuels with respect to the different load conditions are presented in the Figure 6.

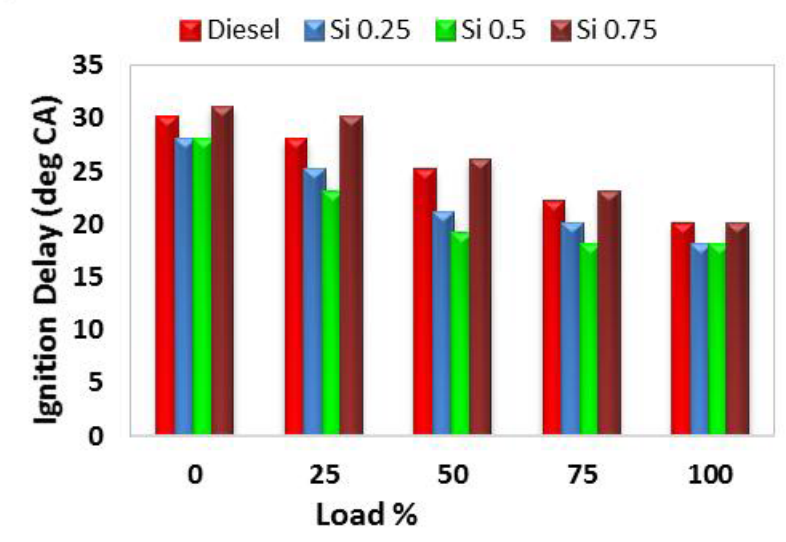

Fig. 6. Ignition delay of the fuels

For diesel without nanoadditive the ignition delay was $30^{\circ} \mathrm{CA}$ at no load condition and it get reduced to $20^{\circ} \mathrm{CA}$ at full load condition. The ignition delay for $\mathrm{Si}$ 0.5 fuel was $28^{\circ} \mathrm{CA}$ at no load condition and $18^{\circ} \mathrm{CA}$ at full load condition. The ignition delay of the fuels decreases with increase in load. Decrease in ignition delay was observed with increase in the quantity of $\mathrm{Si}$ additive upto $0.5 \mathrm{wt} \%$. Further increase in the quantity of $\mathrm{Si}$ additive to $0.75 \mathrm{wt} \%$, increases the ignition delay period. Si 0.75 fuel shows $31^{\circ} \mathrm{CA}$ at no load condition and $20^{\circ} \mathrm{CA}$ at full load condition. With increase in $\mathrm{Si}$ additive more than $0.5 \mathrm{wt} \%$ increases the agglomeration of the particles, which affects the stability of the particles in the fuel. The agglomerated particles tend to settle down in the fuel. This causes an adverse effect in the combustion of the fuel.

The heat release rate curve for the four test fuels were compared in Figure 7. The maximum heat release rate is observed from Si 0.25 fuel. But the area under heat release rate curve is equivalent to that of $\mathrm{Si} 0.5$ fuel. Both the fuels releases their maximum heat energy in between $0^{\circ}$ and $5^{\circ}$ ATDC, which results in effective utilization of the fuel energy. The heat release rate curve for diesel shows that the heat release rate is lower than the former fuels and the maximum heat release rate occurs at $5^{\circ}$ BTDC. The maximum heat release rate by the fuels with Si nanoadditive is the result of increase in calorific value of the fuel by the addition of 
nanoadditive. Si 0.75 fuel shows very low heat release rate than the other test fuels. Increase in ignition delay causes, release of maximum heat release rate at premixed combustion phase $10^{\circ}$ BTDC. Particle agglomeration leads to incomplete combustion of fuel.

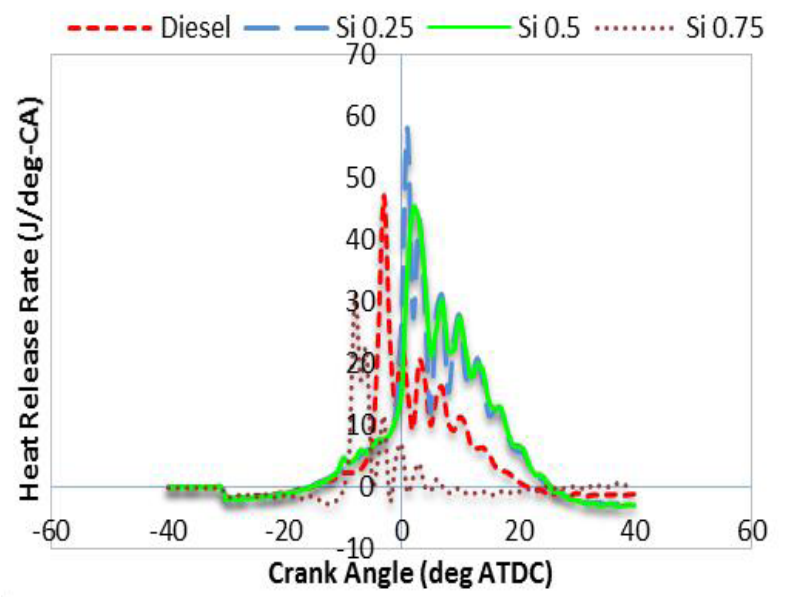

Fig. 7. Heat release rate curves comparison

The pressure rises inside the combustion chamber with respect to the crank angle for the fuels were compared in Figure 8. The pressure rise is a direct effect heat released by the fuel.

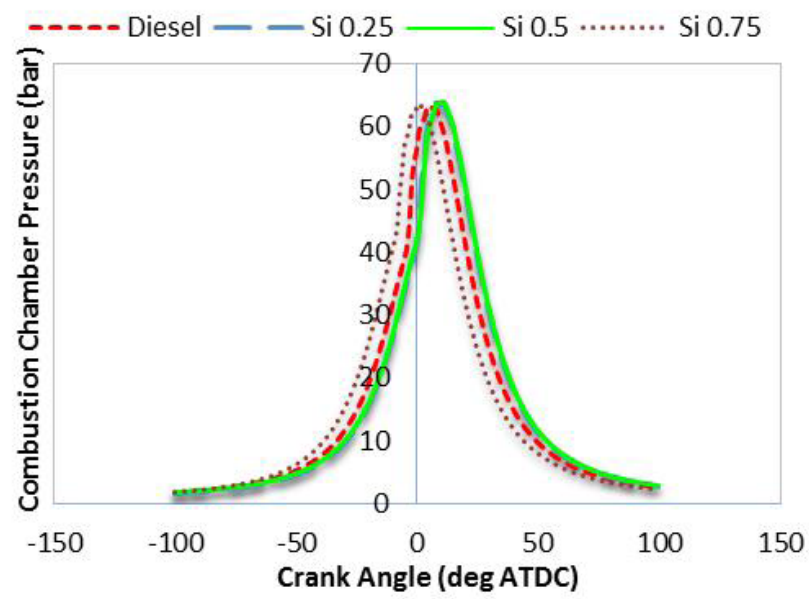

Fig. 8. $P-\Theta$ curves comparison

The maximum pressure created by the fuels during combustion are almost the same, but the time at which maximum pressure generation varies. Si 0.25 fuel and $\mathrm{Si}$ 0.5 fuel shows similar pressure rise curve with maximum pressure at around $10^{\circ}$ ATDC. The maximum pressure rise for diesel fuel occurs at $5^{\circ}$ ATDC. Si 0.75 fuel generates maximum pressure close to TDC. From the heat release rate curve and pressure rise curve it is clear that Si 0.25 fuel and Si 0.5 fuel shows better combustion characteristics than the other two fuels.

\subsection{Performance Analysis}

The performance of a fuel is described by thermal efficiency of the fuel. In this experiment initially the load carrying capacity of the fuels were analyzed. The fuel which produces maximum torque at $100 \%$ loading condition and $1200 \mathrm{rpm}$ constant speed provides the maximum load carrying capacity. Figure 9 shows the torque generated by the test fuels. The maximum load carrying capacity is associated with $\mathrm{Si} 0.5$ fuel. It produces $98.5 \mathrm{Nm}$ at $100 \%$ loading condition and 1200 rpm speed. The fuel with Si 0.25 fuel produces $96 \mathrm{Nm}$ and diesel produces $93 \mathrm{Nm}$ torque in the same working conditions. The maximum heat release rate of the fuels loaded with nanoadditives results in high load carrying capacity.

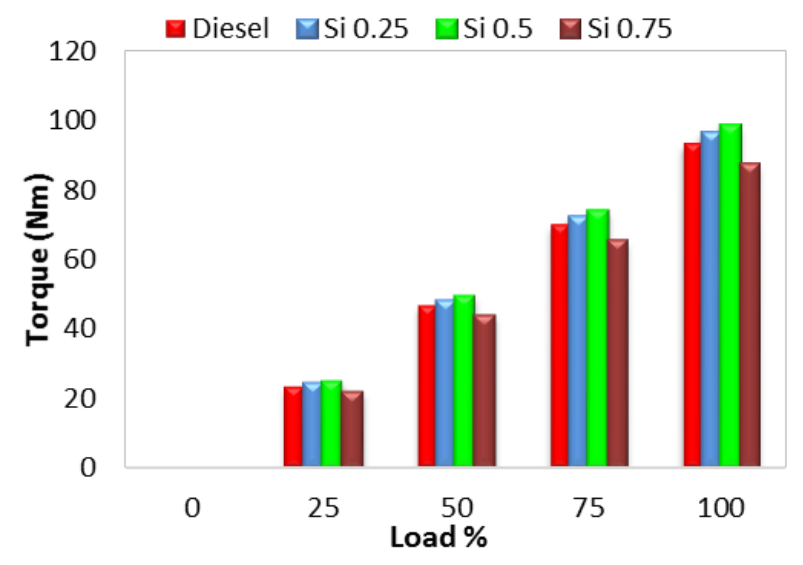

Fig. 9. Load carrying capacity of the fuels

In the following graphs, the nodal points in the curves represents the loading conditions in increasing nature through the $\mathrm{x}$-axis. The graph was plotted between brake power corresponding to the loading conditions in $\mathrm{x}$-axis and the performance values corresponding to the brake power in y-axis. Each fuel produces different brake powers at a loading condition, since constant speed was maintained throughout the testing. This gives more understanding of the fuel characteristics.

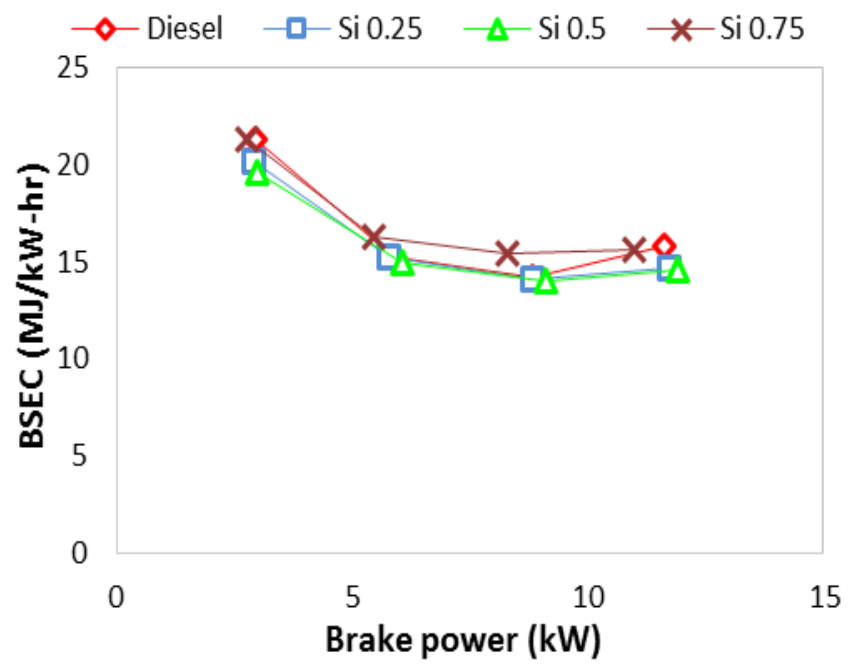

Fig. 10. Brake Specific Energy Consumption curve

Figure 10 presents the Brake Specific Energy Consumption curve for the four fuels. In general, BSEC 
value decreases when load was increased from $25 \%$ to $50 \%$, with further increase in load the BSEC value follows a steady curve. This shows that frictional power is more during low load conditions, so that more energy from the fuel is supplied to overcome the frictional power. The BSEC values of diesel, Si 0.25 , Si 0.5 and $\mathrm{Si}$ 0.75 fuels are $15.8,14.67,14.56,15.65 \mathrm{MJ} / \mathrm{KW}-\mathrm{hr}$ respectively. This clears that $\mathrm{Si} 0.25$ fuel and $\mathrm{Si} 0.5$ fuel provides more energy content than the other fuels. It is found that fuel with Si 0.75 fuel shows less BSEC value than diesel, which doesn't mean that it provides better performance than diesel. Because the corresponding brake power for diesel and Si 0.75 fuel at 100\% loading conditions are $11.64 \mathrm{~kW}$ and $11.22 \mathrm{~kW}$ respectively. Comparatively at same brake power diesel performs better than Si 0.75 fuel.

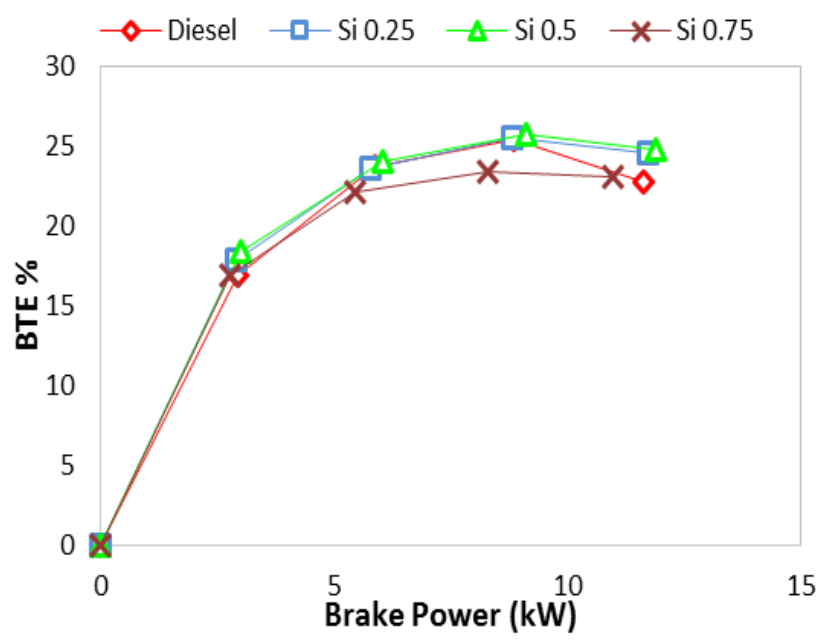

Fig. 11. Brake Thermal Efficiency curves

Brake Thermal Efficiency is inversely related with BSEC. This describes that the thermal efficiency is high when maximum energy is utilized from the fuel. From Figure 11 it is observed that Si 0.5 fuel shows maximum BTE in all the loading conditions. Si 0.25 fuel shows equivalent BTE with Si 0.5 fuel. Diesel shows similar efficiencies at midload conditions as that of Si 0.25 fuel and Si 0.5 fuel but the efficiency is lower at full load condition. This proves the better efficiency of Si 0.25 fuel and Si 0.5 fuel in full load conditions. BTE of Si 0.75 fuel is lower than the other test fuels in all the loading conditions.

\subsection{Emission Analysis}

Several research attempts were made by researchers to enhance the thermal efficiency of the fuel by means of fuel additives, thermal barrier coating [14] etc., it is important to enhance the thermal efficiency as well as simultaneous reduction of emission level is also important. Stringent emission norms are followed by all the countries to control the atmospheric pollution caused by vehicle emission.

The combustion nature of a fuel describe its emission characteristics. The major reason for emission during combustion are described below.
-Incomplete combustion causes $\mathrm{CO}$ emission.

- Poor atomization results in unburned fuel particles which are the sources for $\mathrm{HC}$ emission.

-High heat release rate and maximum combustion timing causes NOx emission.

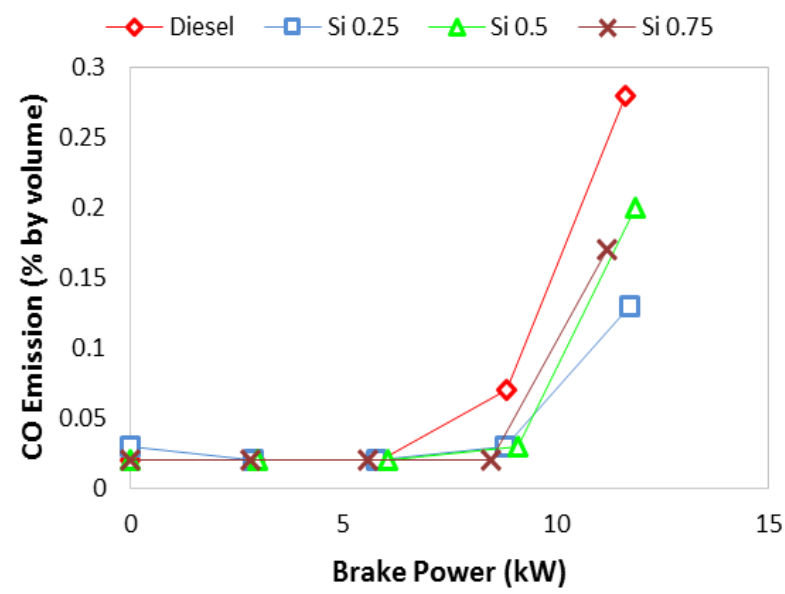

Fig. 12. Carbon Monoxide emission curves

The CO emission rate of the fuels are shown in Figure 12. The emission level is very minimum upto $50 \%$ loading condition. When the loading condition was increased further, increase in $\mathrm{CO}$ emission was observed. At high load conditions more fuel is injected into the combustion chamber. Increase in fuel quantity results in improper fuel mixing which causes incomplete combustion of fuel.

Among the four tested fuels, more $\mathrm{CO}$ emission occurs during diesel combustion. The additive particles mixed in the fuel will absorb the heat energy in the combustion chamber more rapidly than the diesel fuel, which causes evaporation of the fuel droplets. This increases the mixing of fuel with air molecules, thus reduction in $\mathrm{CO}$ emission is observed for additive mixed fuel.

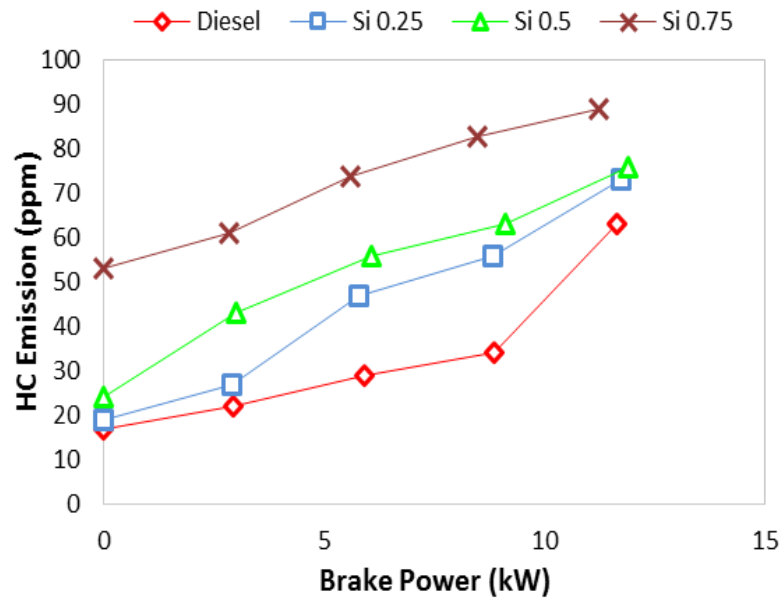

Fig. 13. Hydrocarbon emission curves

Poor atomization results in larger fuel droplets. The inner core of these larger fuel droplets often failed to evaporate and form a fuel-air mixture for combustion. 
These unburned fuel particles are emitted as $\mathrm{HC}$ in the exhaust. Figure 13 represents the $\mathrm{HC}$ emission of the test fuels. Diesel combustion shows minimum $\mathrm{HC}$ emission in comparison with the fuels with additive. As the concentration of the additive is increased, $\mathrm{HC}$ emission is also increased. With the addition of nanoadditives the viscosity of the fuel increases, results in increased droplet size. This causes increased $\mathrm{HC}$ emission in fuels with nanoadditive.

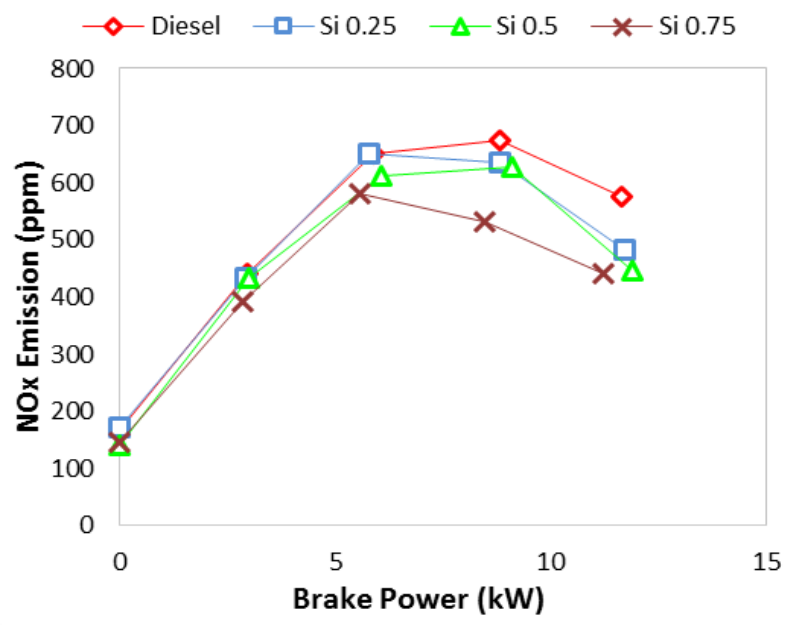

Fig. 14. NOx emission curves

NOx emission generated by the four fuels at various load conditions were presented in Figure 14. Upto 50\% loading condition the test fuels follow similar characteristic curve which tends to increase with increase in load. For $75 \%$ and $100 \%$ load condition $\mathrm{Si}$ 0.75 fuel shows reduced NOx emission. From the heat release rate curve it is clear that the maximum heat released by $\mathrm{Si} 0.75$ fuel is very minimum compared to other fuels, results in reduced NOx emission. The other three fuels shows a similar increasing trend in $75 \%$ load condition.

At full load condition fuel with Si 0.25 fuel and $\mathrm{Si}$ 0.5 fuel emits lower amount of NOx in comparison with diesel. This could also be explained from the heat release curve. The maximum heat release rate for diesel fuel occurs at $5^{\circ}$ BTDC at $100 \%$ load condition. After the maximum heat release rate is observed, further increase in temperature inside the combustion chamber is possible since the piston is approaching TDC. The high temperature availability for prolonged time inside the combustion chamber results in increased NOx emission. While the Si 0.25 fuel and Si 0.5 fuel releases maximum heat energy at around $5^{\circ}$ ATDC. This period corresponds to expansion stroke in which the temperature inside the combustion chamber tends to decrease. This results in reduced NOx emission in comparison with diesel fuel at $100 \%$ loading condition.

Smoke emitted by the test fuels at different load conditions are compared in the Figure 15. Increase in load increases the fuel intake which simultaneously increase the smoke emission. Diesel shows minimum smoke emission compared to the fuels mixed with additives. Increase in the quantity of additive increases the smoke emission. Diesel is a liquid fuel, while additives are solid particles mixed with diesel. After combustion the solid additive particles will be emitted as solid particles from the exhaust. This shows the reason for increase in smoke emission while using additives in the fuel.

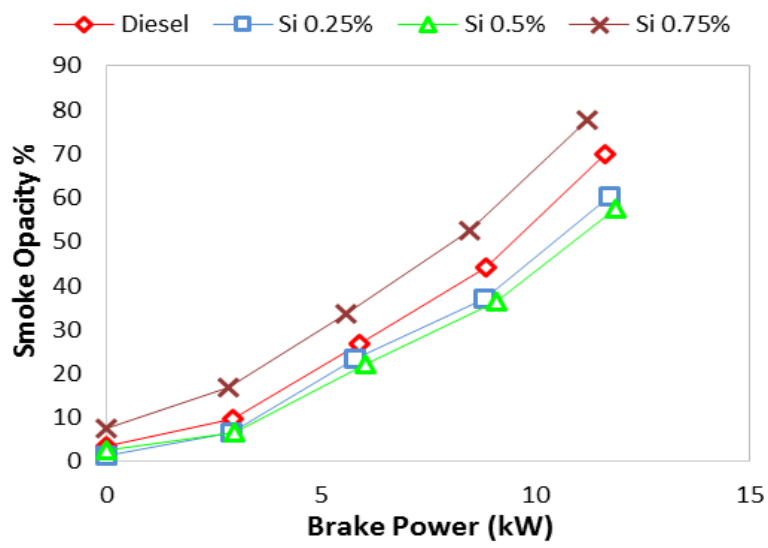

Fig. 15. Smoke opacity curves

\section{Conclusion}

The combustion, performance and emission of a fuel loaded with Si nanoadditive was tested in a twin cylinder diesel engine. Si microparticles were milled in a planetary ball mill for 45 hours. The particle size was reduced from $30 \mu \mathrm{m}$ to $100 \mathrm{~nm}$ and was confirmed by SEM and TEM analysis. The size of the milled particles were in the range between $60 \mathrm{~nm}$ and $100 \mathrm{~nm}$. The elemental composition was analyzed by EDS and the additive material was found to be $97.89 \%$ pure. Nanofuel was prepared by adding three different concentrations $(0.25 \mathrm{wt} \%, 0.5 \mathrm{wt} \%$ and $0.75 \mathrm{wt} \%)$ of silicon nanoadditives in diesel fuel. The physicochemical properties of the test fuels were analyzed and found that with increase in additive concentration a slight increase in calorific value, specific gravity and viscosity were found with decrease in flash point.

The engine analysis proved that the Si 0.5 fuel is better than the other test fuels. Si 0.25 fuel shows similar characteristics as of Si 0.5 fuel but the load carrying capacity of Si 0.5 fuel is more than Si 0.25 fuel. The combustion analysis of the fuel shows that Si 0.5 fuel provides better heat release rate and combustion chamber pressure during combustion. Si 0.5 fuel shows $5.91 \%$ increase in torque generation and $8.95 \%$ increase in BTE than diesel. In case of emission Si 0.5 fuel shows $28.57 \%$ decrease in $\mathrm{CO}$ emission and $27.3 \%$ decrease in NOx emission, with $20.63 \%$ increase in $\mathrm{HC}$ emission in comparison with diesel. From the results it is clear that Si 0.5 fuel provides better combustion, performance and emission characteristics than diesel.

\section{References}

1. I. Javed, S. W. Baek, and K. Waheed, Combust. Flame, 162, pp. 774-787, (2015). 
2. Y. Gan and L. Qiao, Combust. Flame, 158, pp. 354368, (2011).

3. R. A. Yetter, G. A. Risha, and S. F. Son, Proc. Combust. Inst., 32 II, pp. 1819-1838, (2009).

4. Sadhik Basha and R. B. Anand, Alexandria Eng. J., 53, pp. 259-273, (2014).

5. Yoon and S. W. Baek, www.ijm-me.org Int. J. Mater. Mech. Eng., 4, pp. 44-49, (2015).

6. M. A. Lenin, M. R. Swaminathan, and G. Kumaresan, Fuel, 109, pp. 362-365, (2013).

7. Y. Gan and L. Qiao, pp. 1-12, (2010).

8. M. Jones, C. H. Li, A. Afjeh, and G. Peterson, Nanoscale Res. Lett., 6, p. 246, (2011).

9. E. L. Dreizin, Combust. Flame, 117, pp. 841-850, (1999).

10. Javed, S. Wook, K. Waheed, G. Ali, and S. Oh, "Evaporation characteristics of kerosene droplets with dilute concentrations of ligand-protected aluminum nanoparticles at elevated temperatures."

11. T. Miller and J. Herr, AIAA, pp. 1-10, (2004).

12. Javed, S. W. Baek, and K. Waheed, Exp. Therm. Fluid Sci., 56, pp. 33-44, (2014).

13. V. Sajith, C. B. Sobhan, and G. P. Peterson, Adv. Mech. Eng., (2010).

14. Ganapathy, S., Appancheal, A., and Velusamy, R., " SAE Technical Paper 2017-28-1981, (2017) 